\title{
LUT
}

University

\section{Statistical analysis of sustainable production of algal biomass from wastewater treatment process}

Ambat Indu, Tang Walter, Sillanpää Mika

This is a Author's accepted manuscript (AAM) version of a publication

published by Elsevier

in Biomass and Bioenergy

DOI: $\quad 10.1016 /$ j.biombioe.2018.10.016

Copyright of the original publication: @ 2018 Elsevier Ltd

Please cite the publication as follows:

Ambat, I., Tang, W., Sillanpää, M. (2019). Statistical analysis of sustainable production of algal biomass from wastewater treatment process. Biomass and Bioenergy, vol. 120, pp. 471-478.

DOI: 10.1016/j.biombioe.2018.10.016

This is a parallel published version of an original publication.

This version can differ from the original published article. 
1 Statistical analysis of sustainable production of algal biomass from wastewater

2 treatment process

3

$4 \quad$ Indu Ambat ${ }^{\mathrm{a} *}$, Walter Z. Tang ${ }^{\mathrm{b}}$, Mika Sillanpää ${ }^{\mathrm{a}, \mathrm{b}}$

$5{ }^{a}$ Laboratory of Green Chemistry, School of Engineering Science, Lappeenranta University of

6 Technology, Sammonkatu 12, FI-50130 Mikkeli, Finland

$7 \quad \mathrm{~b}$ Department of Civil and Environmental Engineering, Florida International University, Miami,

$8 \quad$ FL-33174, USA

9

10 


\section{Abstract}

12 Algal biodiesel is one of the most promising renewable and eco-friendly source of energy for

13 transportation, when algae is produced from wastewater. During the process, both goals of 14 biodiesel production and wastewater treatment could be achieved simultaneously. However, the 15 optimal condition for algae production remained unanswered. Algal biodiesel could be produced 16 from various wastewater treatments. In this study the relationship between biomass production 17 versus lipid productivity in various wastewater sources is statistically analyzed. Chemical 18 oxidation demand, total nitrogen, total phosphorus, and $\mathrm{CO}_{2}$ sequestration could be achieved 19 during the production of different algal biomass in numerous type of wastewater effluent. The 20 regression of different system models and interpretation of linear coefficients were represented in 21 this statistically approached studies. Apart from that the paper also discuss the uncertainty of linear 22 regressions using Monte Carlo method, influence of physical parameters on biomass production, 23 energy potential and efficiency of nutrient removal using different phototrophic systems. 
36 Key words: Biomass, Chemical oxidation demand, Total nitrogen, Total phosphorus, Wastewater 


\section{Introduction}

41 The main source of energy for the world is fossil fuels such as petroleum products, methane, and

42 coal. The non-renewable nature of fossil fuels leads to scarcity of energy which have aroused great

43 interest in search for alternative fuels [1]. Rapid increase in population results in expeditious

44 utilization of fossil fuels which lead to two major issues, direct environmental pollution and global

45 warming. To meet the challenges, alternative fuels with renewable, biodegradable and

46 environmental friendly nature are under intensive investigation [2-4]. Biodiesel is one of these

47 renewable fuels because it possess all the features needed as a fossil fuel substitute and it could be

48 produced from numerous feedstocks such as vegetable oil, algal oil and animal fat/oil [5] .

49 The increase of global $\mathrm{CO}_{2}$ emission demands effective and efficient techniques for the 50 sequestration of $\mathrm{CO}_{2}$ [6]. In 1997, the Kyoto protocol suggested that, for the reduction of oil and

51 to meet the GHG reduction targets, affordable supplies of clean, secure transportation fuels using

52 low-carbon technologies have to be found [7]. Ever since, significant attention has been devoted

53 to develop biofuels, for example from microalgal sources. Due to growing demand of petroleum

54 and significantly larger issues regarding global warming and greenhouse effect as a part of ignition

55 of fossil fuels, a substantial importance has been given to the concept of using microalgae as a fuel

56 source. Benefits of microalgae-based biofuels are greater production yields and the ability to

57 capture $\mathrm{CO}_{2}$. Therefore, algal fuel has great importance due to its environmental friendly nature to

58 decrease global warming [8-10]. Biodiesel can be the best renewable energy option because it is

59 free from sulphur and aromatics along with that it also reduced emission carbondioxide, 
60 hydrocarbon and particulate matter. Algal biofuels can lower greenhouse gas emission from

61101,000 grams of $\mathrm{CO}_{2}$ equivalent per million British thermal units to 55, 440 grams [6].

62 Harder and Witch were the first to propose to use algae for energy and production in 1942. In the 631950 s, carbohydrate fraction of algal cells was used for the production of methane gas under 64 anaerobic digestion by Meier (1955) and Oswald and Golueke (1960) [11]. In the early 1970s, the 65 sharp raising of energy price led to a push for energy production from aquatic species mainly algae 66 gained major attention [11]. In recent years, the algal cultivation gained greater attention due to its 67 various applications such as an alternative feedstock for biodiesel production, nutrient control in wastewater remediation process as well as low cost method for biomass harvesting[12].

69 Microalgae has great potential to assimilate nutrients efficiently and effectively when algal species 70 were grown in wastewater. Rich nutrients in wastewater provide better growth rate of algal species 71 depending upon the algal strains or species [13]. Recently, there is plenty of work related to 72 treatment of various kinds of wastewater such as dairy wastewater, piggery wastewater, olive oil 73 mill wastewater, brewerywastewater, municipal sewage sludge, molasses wastewaters, soybeans 74 processingwastewater, and petrochemical wastewater using algal culture systems [14-20]. Shoener 75 et al., reported that wastewater treatment can be energy positive with transformation of organic 76 matter by anaerobic digestion and removal of nutrients by phototrophic technologies especially 77 using algae [21]. Combination of wastewater treatment with algae cultivation for biodiesel 78 production could lead to a sustainable, cost effective and eco-friendly algal based energy 79 production process. Algae uses the nutrients present in the wastewater for its growth, which offer 80 an effective nutrient treatment technology along with algal biomass for biodiesel production 81 without fresh water [12, 13, 22]. 
82 The main objectives of this paper are to: 1) statistically analyze optimal conditions for algae

83 production using wastewater from variety sources such residential or industry; 2) develop

84 predictive equations of algae biomass production using chemical oxygen demand (COD), total

85 nitrogen and total phosphorus, as well as $\mathrm{CO}_{2}$ fixation rate by different kinds of algal species using

86 regression analysis; and 3) validate the correlation equations using other independently reported

87 research results.

\section{Database and statistical methods}

89

The data are obtained from published peer reviewed papers. The collected data were organized to

91 present details of biomass production in various kinds of wastewater. In spite of that, there are

92 other various databases, which are shown in this study, such as the influence of nutrient

93 concentration on algal biomass production, relationship between biomass production and lipid

94 productivity in different kinds of waste water and $\mathrm{CO}_{2}$ sequestration capabilities of several algal

95 species. Therefore, the database helps to perform regression analysis of biomass produced with

96 respect to lipid productivity, COD, total nitrogen and total phosphorus content in wastewater.

97 SPSS was used to obtain linear regression analysis and MatLab was used to determine uncertainity 98 of the linear regression.

\section{Results and discussion}


105 The algal biomass production and lipid productivity data of various algal species in different 106 wastewater effluents are shown in table 1 . Table 1 also explains the ability of several microalgal 107 species to grow in wastewater resources with high lipid content. The key factor in biodiesel 108 production and considerable cost reduction and commercialization of algal biofuel production 109 could be achieved with high lipid productivity. The Chlamydomonas reinhardtii (biocoil-grown) 110 grown in municipal centrate effluent showed higher biomass production as well as lipid 111 productivity.

113 Table 1. The biomass and lipid productivities of some of the microalgal species grown in different 114 wastewater resources.

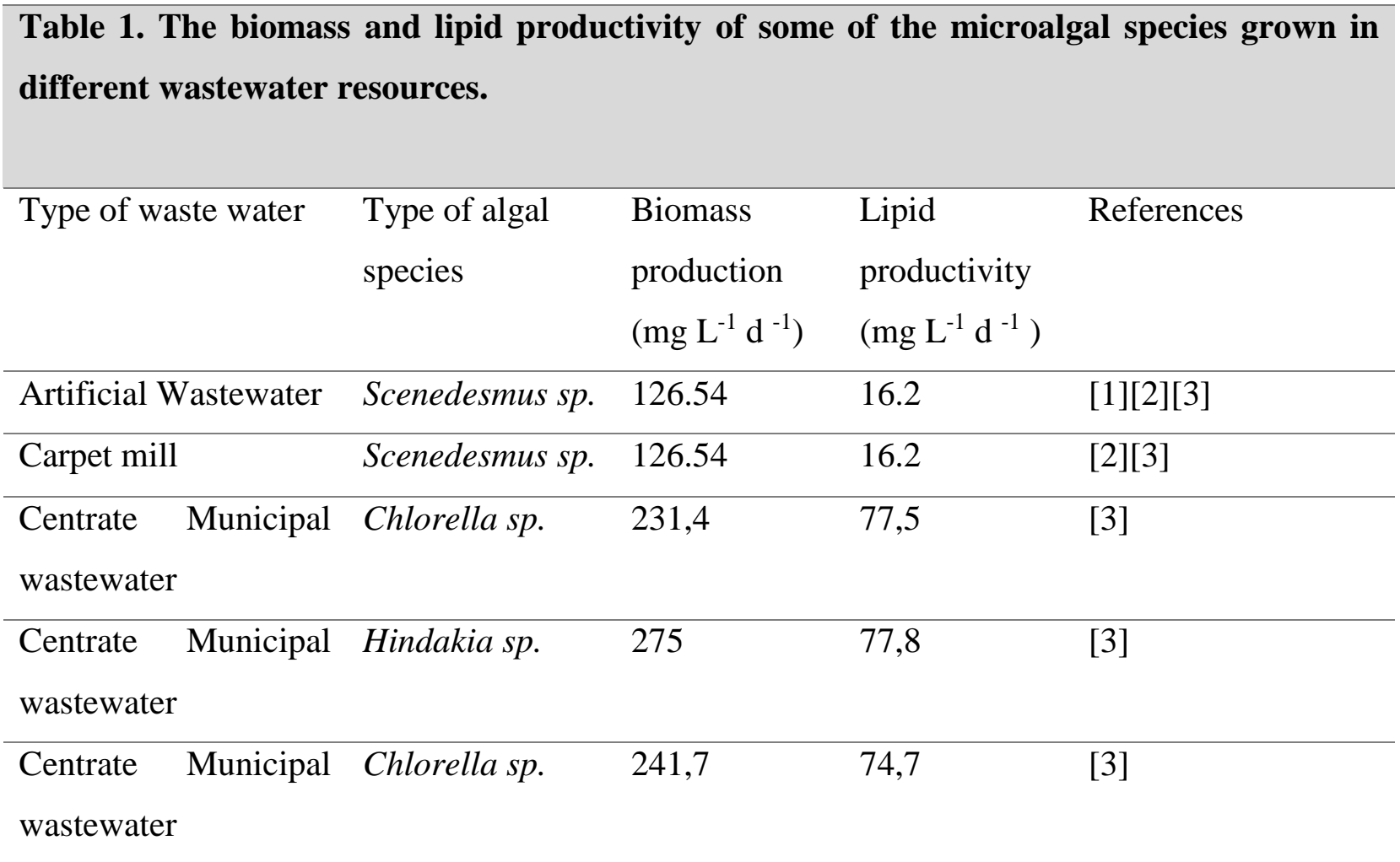




\begin{tabular}{|c|c|c|c|c|}
\hline $\begin{array}{l}\text { Centrate Municipal } \\
\text { wastewater }\end{array}$ & Scenedesmus sp. & 247,5 & 75,5 & [3] \\
\hline $\begin{array}{l}\text { Concentrated } \\
\text { Municipal wastewater }\end{array}$ & $\begin{array}{l}\text { Auxenochlorella } \\
\text { protothecoides }\end{array}$ & 268,8 & 77,7 & {$[3]$} \\
\hline Municipal (centrate) & $\begin{array}{l}\text { Chlamydomonas } \\
\text { reinhardtii } \\
\text { (biocoil-grown) }\end{array}$ & 2000 & 505 & {$[1][4]$} \\
\hline $\begin{array}{l}\text { Municipal (secondary } \\
\text { treated) }\end{array}$ & $\begin{array}{l}\text { Scenedesmus } \\
\text { obliquus }\end{array}$ & 26 & 8 & {$[1][4]$} \\
\hline $\begin{array}{l}\text { Municipal (secondary } \\
\text { treated) }\end{array}$ & $\begin{array}{l}\text { Botryococcus } \\
\text { braunii }\end{array}$ & 345,6 & 62 & {$[1][4]$} \\
\hline $\begin{array}{l}\text { Municipal (primary } \\
\text { treated }+\mathrm{CO} 2 \text { ) }\end{array}$ & $\begin{array}{l}\text { Mix of Chlorella } \\
\text { sp., } \\
\text { Micractinium } \\
\text { sp., Actinastrum } \\
\text { sp. }\end{array}$ & 270,7 & 24,4 & {$[1][4]$} \\
\hline $\begin{array}{l}\text { Agricultural (piggery } \\
\text { manure with high } \\
\text { NO3-N) }\end{array}$ & B. braunii & 34 & 4,5 & {$[1][4]$} \\
\hline $\begin{array}{l}\text { Industrial (carpet mill, } \\
\text { untreated) }\end{array}$ & $\begin{array}{l}\text { Dunaliella } \\
\text { tertiolecta }\end{array}$ & 28 & 4,3 & {$[1][4]$} \\
\hline $\begin{array}{l}\text { Industrial (carpet mill, } \\
\text { untreated) }\end{array}$ & $\begin{array}{l}\text { Pleurochrysis } \\
\text { carterae }\end{array}$ & 33 & 4 & {$[1][4]$} \\
\hline
\end{tabular}

115

116

117 
119 The Fig1, shows the linear regression between biomass and lipid productivity, which can be 120 expressed as follows:

$$
Y=0.25 x-2.9 \quad R^{2}=0,982
$$

122 Where: $\mathrm{y}$ is biomass production $\left(\mathrm{mg} \mathrm{L}^{-1} \mathrm{~d}^{-1}\right)$ and $\mathrm{x}$ is lipid productivity rate $\left(\mathrm{mg} \mathrm{L}^{-1} \mathrm{~d}^{-1}\right)$

123 The regression equation shows linear correlation between lipid productivity in various waste water 124 resources depends on biomass production. Biomass production can explain $93.7 \%$ of the 125 variability of our dependent variable, which is lipid productivity. Residual plots denotes the 126 difference between the observed value of the dependent variable, lipid productivity of algal species 127 in different wastewater resources and the predicted value. The residual plots shows random pattern 128 indicating good fit to the linear model. 

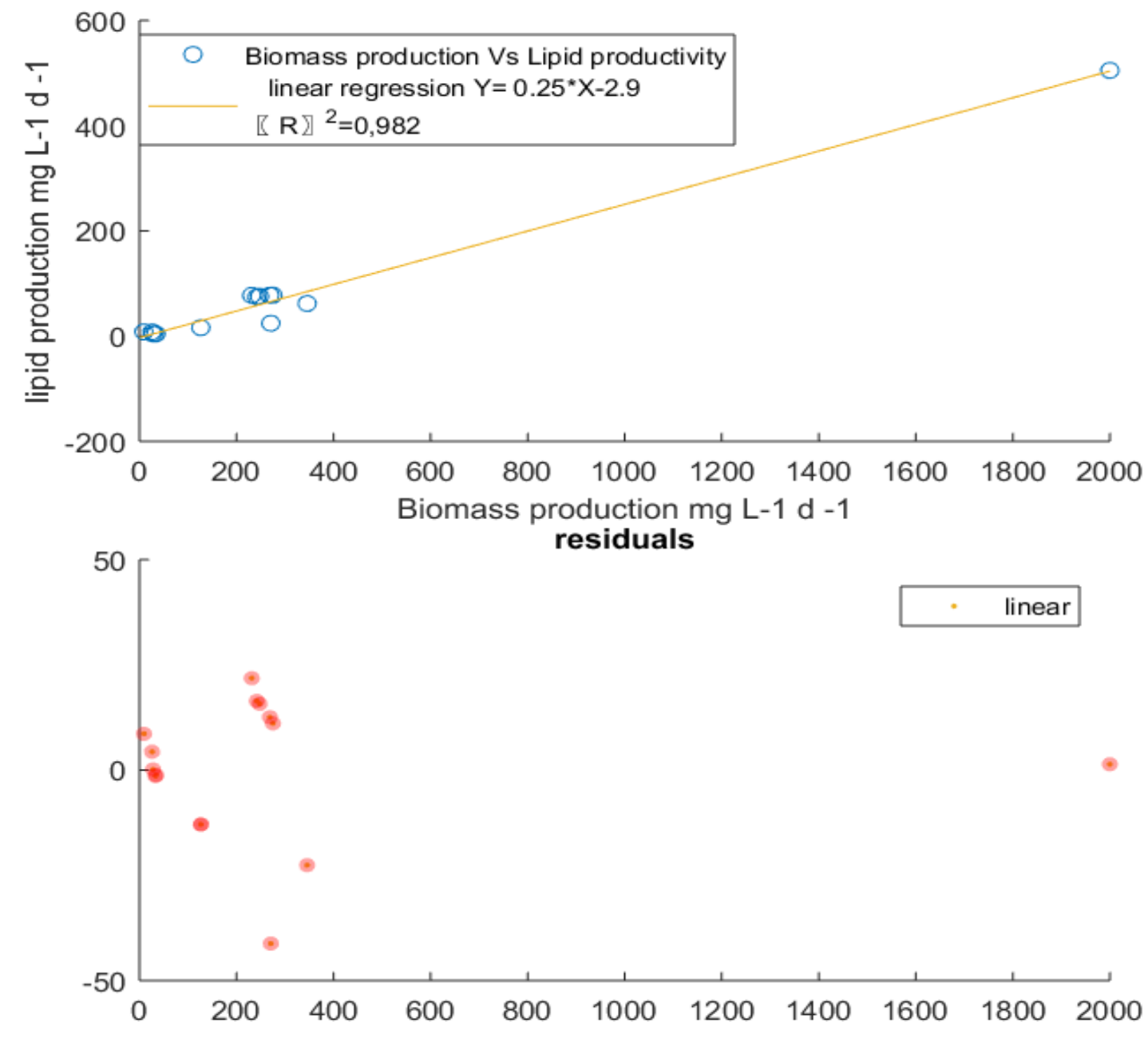

130 Fig1. Regression between biomass production $\mathrm{mg} \mathrm{L}^{-1} \mathrm{~d}^{-1}$ with respect to lipid productivity $\mathrm{mg} \mathrm{L}^{-}$

$131{ }^{1} \mathrm{~d}^{-1}$ of various algal species in different wastewater resources

132 
135 Zhu et al., (2013) cultivated the microalgae, Chlorella zofingiensis, in piggery wastewater effluent 136 under different concentration of nutrients such as COD, TN and TP as depicted in Table 2. 137 Therefore, the effect of nutrients concentration on biomass production could be quantified. The 138 maximum biomass production of Chlorella zofingiensis, $296.16 \mathrm{mgL}^{-1} \mathrm{~d}^{-1}$ was observed with 139 concentrations of COD, TN, TP $1,900 \mathrm{mg} \mathrm{L}^{-1}, 80 \mathrm{mg} \mathrm{L}^{-1}, 85 \mathrm{mg} \mathrm{L}^{-1}$ respectively [23].

141 Table 2. Effect of COD, TN, TP concentration in piggery wastewater for biomass production of 142 Chlorella zofingiensis [23].

\begin{tabular}{|c|c|c|c|}
\hline $\mathrm{COD}\left(\mathbf{m g ~ \mathbf { L } ^ { - 1 }}\right)$ & $\mathrm{TN}\left(\mathrm{mg} \mathrm{L}^{-1}\right)$ & $\mathrm{TP}\left(\mathrm{mg} \mathrm{L}^{-1}\right)$ & $\operatorname{Biomass}\left(\mathrm{mg} \mathrm{L}^{-1} \mathrm{~d}^{-1}\right)$ \\
\hline 3500 & 148 & 156 & 267.81 \\
\hline 2500 & 106 & 111 & 273.33 \\
\hline 1900 & 80 & 85 & 296.16 \\
\hline 1300 & 55 & 58 & 216.63 \\
\hline 800 & 34 & 36 & 160.34 \\
\hline 400 & 17 & 18 & 106.28 \\
\hline
\end{tabular}

143

145 The Fig 2 represents that the linear regression between biomass production and COD 146 concentration in piggery wastewater system can be obtained as follows:

$147 \quad Y=0.0528 x+128,64$

$R^{2}=0,667$

148 Where: $\mathrm{y}$ is biomass production $\left(\mathrm{mg} \mathrm{L}^{-1} \mathrm{~d}^{-1}\right)$ and $\mathrm{x}$ is COD concentration $\left(\mathrm{mg} \mathrm{L}^{-1}\right)$ 
149 The linear regression between biomass production and $\mathrm{TN}$ concentration in piggery wastewater 150 system can be obtained as follows:

$151 Y=1.2462 x+128.71$

$$
R^{2}=0,665
$$

152 Where: $\mathrm{y}$ is biomass production $\left(\mathrm{mg} \mathrm{L}^{-1} \mathrm{~d}^{-1}\right)$ and $\mathrm{x}$ is $\mathrm{TN}$ concentration $\left(\mathrm{mg} \mathrm{L}^{-1}\right)$

153 The linear regression between biomass production and TP concentration in piggery wastewater 154 system was shown in Figure 5 and can be depicted as follows:

$155 Y=1.1876 x+128,25$

$$
R^{2}=0,668
$$

156 Where: $\mathrm{y}$ is biomass production $\left(\mathrm{mg} \mathrm{L}^{-1} \mathrm{~d}^{-1}\right)$ and $\mathrm{x}$ is TP concentration $\left(\mathrm{mg} \mathrm{L}^{-1}\right)$

157 The above regression analysis clearly shows that biomass production in piggery wastewater system 158 depends on COD, TN and TP concentration correspondingly. COD, TN and TP can explain 66.7\%, $15966.5 \%$ and $66.8 \%$ of the variability of our dependent variable, biomass production respectively. 160 The residual plots denotes the difference between the observed value of the dependent variable, 161 biomass production of Chlorella zofingiensis in piggery wastewater resources and the predicted 162 value. The residual plots shows random pattern's decent fit to the linear model. 

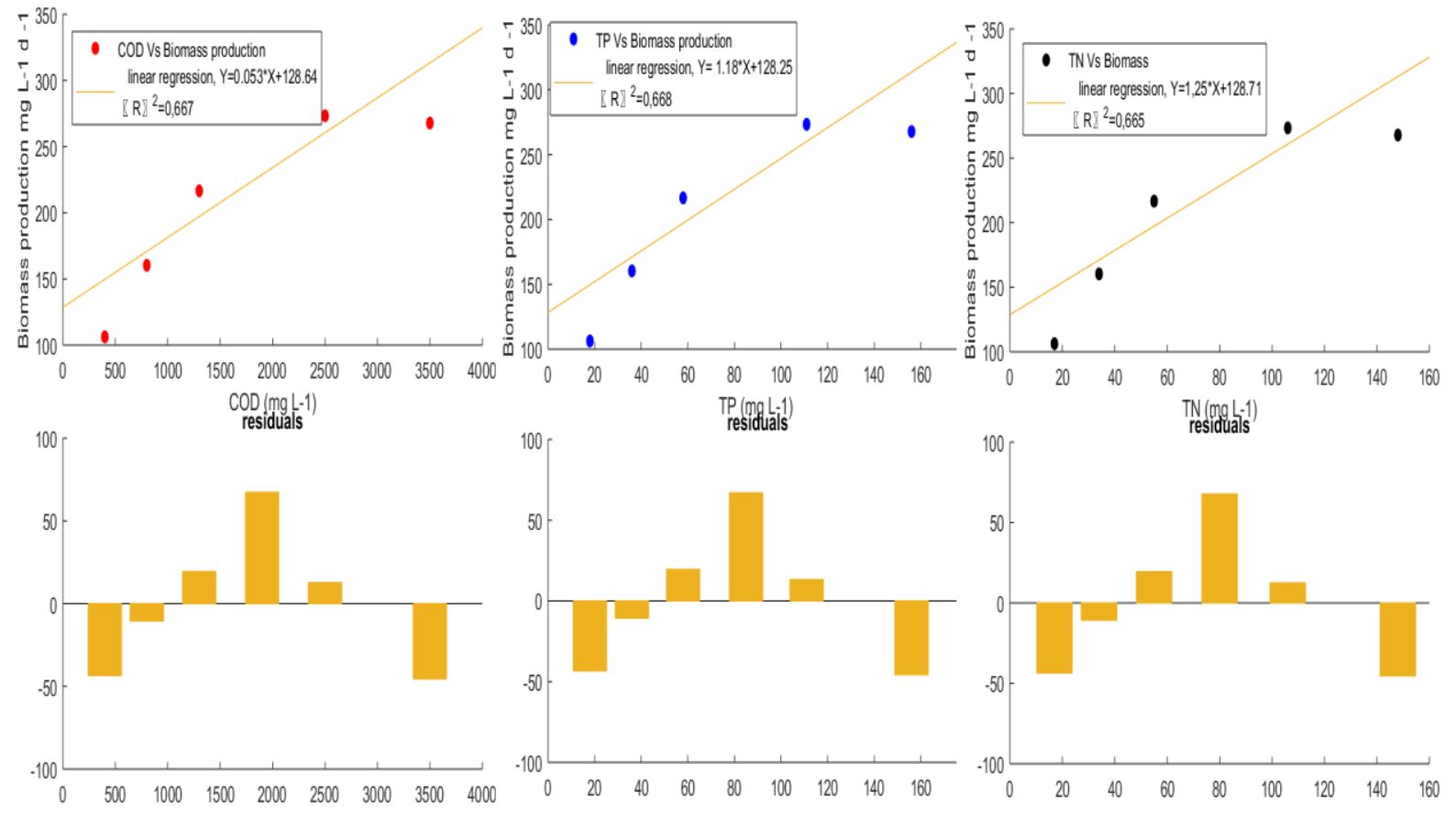

Fig2. Regression between biomass productions of Chlorella zofingiensis $\left(\mathrm{mg} \mathrm{L}^{-1} \mathrm{~d}^{-1}\right)$ with respect to $\mathrm{COD}\left(\mathrm{mg} \mathrm{L}^{-1}\right)$, $\mathrm{TN}\left(\mathrm{mg} \mathrm{L}^{-1}\right)$, $\mathrm{TP}\left(\mathrm{mg} \mathrm{L}^{-1}\right)$ in piggery wastewater effluent

\subsection{Relationship between various algal biomass production and $\mathrm{CO}_{2}$}

Based on table 3, the majority of algal species preferred lower concentration of $\mathrm{CO}_{2}$ where as some

171 algal species especially Chlorella species showed capacity to withstand high concentration of $\mathrm{CO}_{2}$.

172 Moreover the highest biomass production was observed at lower concentration of $\mathrm{CO}_{2}$.

173 Carbondioxide tolerance limits were specific for algal species, so several studies aimed at

174 determining the optimum $\mathrm{CO}_{2}$ concentration for each algal species [24]. Table 3 shows the 175 capabilities of various microalgal species in $\mathrm{CO}_{2}$ sequestration under various $\mathrm{CO}_{2}(\% \mathrm{v} / \mathrm{v})$ 176 concentration [24]. 
177 Table 3. Biomass production for different microalgal species under various $\mathrm{CO}_{2}(\% \mathrm{v} / \mathrm{v})$ 178 concentration

\section{Table 3. Biomass production for different microalgal species under various $\mathrm{CO}_{2}(\% \mathrm{v} / \mathrm{v})$ concentration}

Microalgal species $\mathrm{CO}_{2}(\% \mathrm{v} / \mathrm{v}) \quad$ Biomass production

\begin{tabular}{lcc} 
& & $\left(\mathrm{mg} \mathrm{L}^{-1} \mathrm{~d}^{-1}\right)$ \\
\hline Chlorella sp. KRl & 70 & 118 \\
\hline Dunaliella sp & 12 & 71 \\
\hline Scenedesmus obliquus AS-6-1 & 20 & 380 \\
\hline Nannochloris sp. & 15 & 350 \\
\hline Chlorella sp. & 50 & 950 \\
\hline Chlorella sp. & 20 & 700 \\
\hline Chlorococcum littorale & 20 & 530 \\
\hline Aphanothece microscopic Nageli & 15 & 1250 \\
\hline Chlorella kessleri & 12 & 220 \\
\hline Chlorella vulgaris & 18 & 520 \\
\hline Scenedesmus obliquus SJTU & 20 & 134 \\
\hline S. obtusiusculus & & \\
\hline Scenedesmus sp. & 10 & \\
\hline
\end{tabular}

179

180 The Fig. 3 show that there is no apparent correlation between the unit biomass productions with 181 the volume concentration of $\mathrm{CO}_{2}$. The correlation coefficients $\left(\mathrm{R}^{2}\right)$ for the linear relationships of 182 the biomass production, and the $\mathrm{CO}_{2}$ concentration are extremely low of $4 \times 10^{-5}$. The major reason 
183 for no correlation could be different experimental reactors and processes. Therefore, different $\mathrm{CO}_{2}$

184 utilization rate and efficients could not be used as a predictor for algal biomass production.
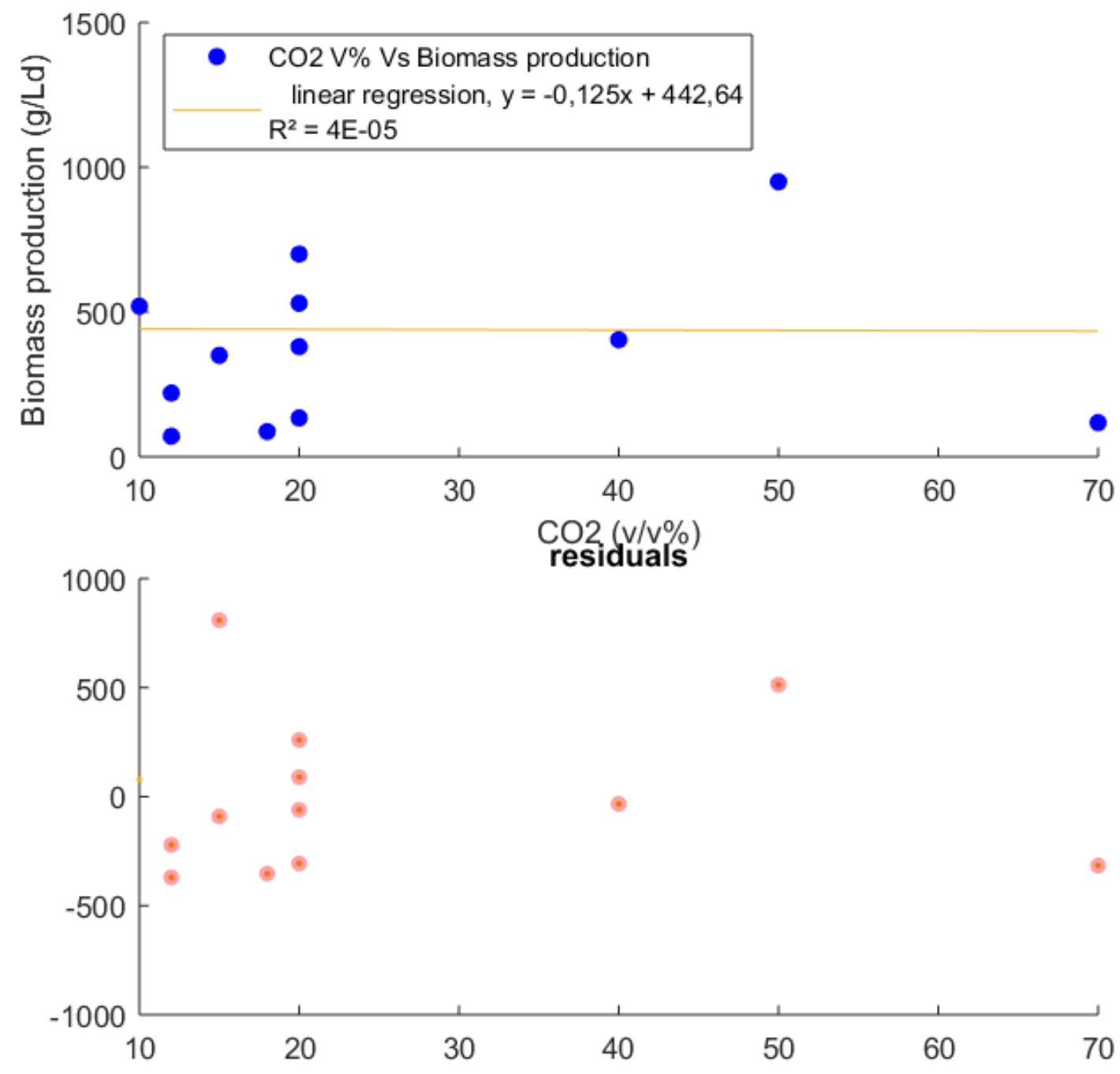

185

186 Fig3. Regression between biomass production $\left(\mathrm{mg} \mathrm{L}^{-1} \mathrm{~d}^{-1}\right)$ with respect to $\mathrm{CO}_{2}$ concentration $187(\% \mathrm{v} / \mathrm{v})$ of various algal species [24]. 
Table 4. Unit biomass production of various microalgal species in $\mathrm{CO}_{2}$ sequestration [6].

\section{Table 4. Unit biomass production of various microalgal species in $\mathrm{CO}_{2}$ sequestration [6].}
Algal species
Biomass production $\left(\mathrm{g} \mathrm{L}^{-1} \mathrm{~d}^{-1}\right)$

\begin{tabular}{lcc}
\hline Chlorella vulgaris & 2,03 & 0,43 \\
\hline Chlorella kessleri & 0,87 & 0,163 \\
\hline Scenedesmus obliquss & 0,142 & 0,253 \\
\hline Chlorococcum littorale & 0,12 & 0,2 \\
\hline Chlorella sorokiniana & 0,338 & 0,619 \\
\hline Anabaena sp. ATCC 33047 & 0,31 & 1,45 \\
\hline Spirulina platensis & 2,18 & 0,32 \\
\hline Haematococcus pluvialis & 0,076 & 0,143 \\
\hline Botryococcus braunii SI-30 & 1,1 & 1
\end{tabular}

197 The linear regression between biomass production and $\mathrm{CO}_{2}$ fixation rate by different algal species 198 was shown in Figure 4 and can be depicted as follows:

$Y=-0.019 x+0.52 \quad R^{2}=0,0012$

200 Where: $\mathrm{y}$ is $\mathrm{CO}_{2}$ fixation rate $\left(\mathrm{g} \mathrm{L}^{-1} \mathrm{~d}^{-1}\right)$ and $\mathrm{x}$ is biomass production $\left(\mathrm{g} \mathrm{L}^{-1} \mathrm{~d}^{-1}\right)$ 
201 In this regression analysis, biomass production and $\mathrm{CO}_{2}$ fixation rate less depends on each other.

202 Biomass production of various algal species can only explain $0.12 \%$ of the variability of our 203 dependent variable, $\mathrm{CO}_{2}$ fixation rate.

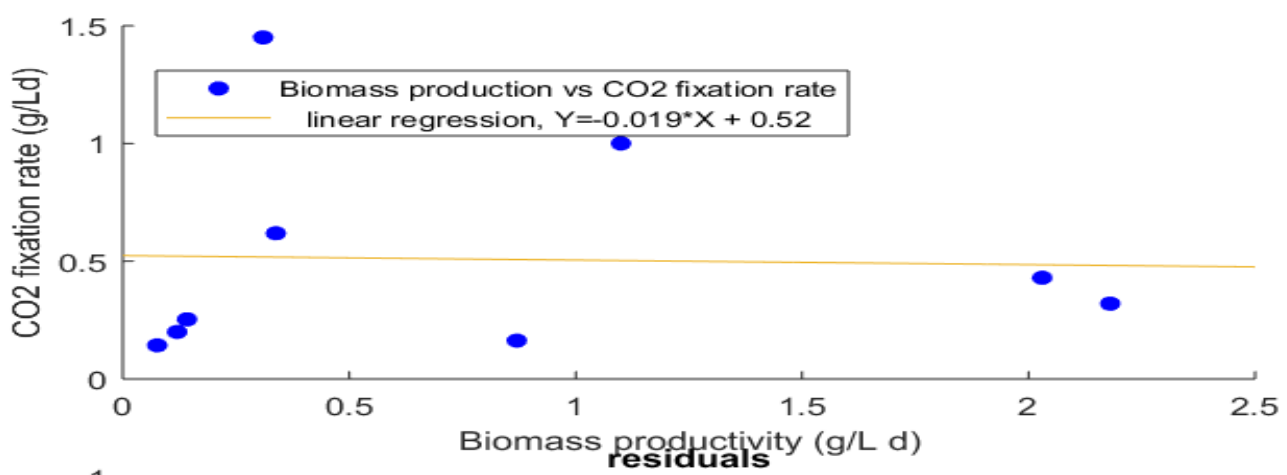

206

207 Fig4. Regression between biomass production $\mathrm{g} \mathrm{L}^{-1} \mathrm{~d}^{-1}$ with respect to $\mathrm{CO}_{2}$ fixation rate $\mathrm{g} \mathrm{L}^{-1} \mathrm{~d}^{-1}$ 208 of various algal species in wastewater resources [6].

212 Correlation equation 1 in table 5 shows summary and parameter estimates of multiple regression 213 analysis of biomass production with respect to COD, TN, TP in piggery wastewater and model 2 
214 represents the $\mathrm{CO}_{2}$ fixation rate by different algal species. The correlation coefficiency, $\mathrm{R}^{2}$, 215 measures the quality of the prediction of the biomass production, the dependent variable. When 216 multivariable regression is used, parameters such as $\mathrm{COD}, \mathrm{TN}, \mathrm{TP}$, and $\mathrm{CO}_{2}$ explain $98.5 \%$ 217 biomass production. On the other hand, $\mathrm{CO}_{2}$ does not show any linear correlationship with biomass 218 production as in model 2.

219 Table 5. Model summary and parameter estimates of regression analysis of biomass production 220 with respect to various predictors

$\begin{aligned} & \text { Table 5. Model summary and parameter estimates of regression analysis } \\
& \text { of biomass production with respect to various predictors }\end{aligned}$
\begin{tabular}{lcccc} 
& & & \\
\hline Model & R Square & Adjusted & R & Std. Error of \\
& & Square & the Estimate \\
\hline $\mathbf{1}$ & $0,992^{\mathrm{a}}$ & 0,985 & 0,962 & 14,352 \\
\hline $\mathbf{2}$ & $0,035^{\mathrm{a}}$ & 0,001 & 0,141 & 0,477
\end{tabular}

a. Predictors: (Constant), TP, TN, COD, $\mathrm{CO}_{2}$

b. Dependent variable: Biomass production[23,24]

223 Based on Table 6, model 1 the F-ratio indicates whether the overall regression model is a good fit 224 for the data. The Table 6 also shows that the independent variables such as COD, TN and TP, are 225 statistically significant to predict the dependent variable biomass production, $\mathrm{F}(3,2)=205.969$, 226 in piggery wastewater. The statistical prediction of dependent variable, that is biomass production 227 of various algal species was determined with help of $\mathrm{CO}_{2}$ as an independent variable and shown 228 as $\mathrm{F}(1,4)=1833.243$. 
229 Table 6. Statistical significance of regression analysis

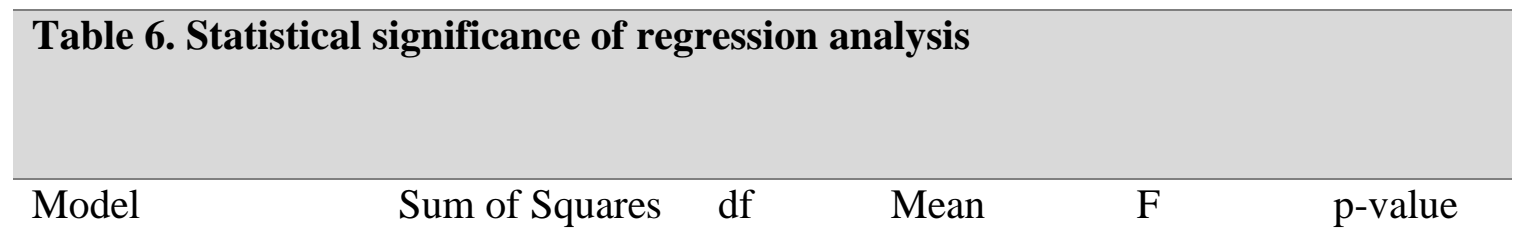

Square

\begin{tabular}{|c|c|c|c|c|c|c|}
\hline 1 & Regression & 27021,152 & 3 & 9007,051 & 43,730 & 0,022 \\
\hline & Residual & 411,939 & 2 & 205,969 & & \\
\hline
\end{tabular}

27433,091

\begin{tabular}{|c|c|c|c|c|c|}
\hline a. Dependent V & le: Bio & & & & \\
\hline b. Predictors: ( & ant), $\mathrm{T}]$ & & & & \\
\hline 2 Regression & ,007 & 1 & ,007 &, 009 & ,928 \\
\hline Residual & 5,378 & 7 & ,228 & & \\
\hline Total & 5,385 & 8 & & & \\
\hline
\end{tabular}

a. Dependent Variable: Biomass

b. Predictors: (Constant), $\mathrm{CO}_{2}$

231

232 Based on Table 7, the general form of the equation to predict biomass production from COD, TN,

233 TP, is:

234 Predicted biomass production $=-920,535+(0,041 \times C O D)+(9,102 \times T N)+$

$235 \quad(3,910 \times T P)$

236 Where: $\mathrm{y}$ is biomass production $\left(\mathrm{mg} \mathrm{L}^{-1} \mathrm{~d}^{-1}\right)$ and predictors are COD, TN, TP concentration (mg

$237 \mathrm{~L}^{-1}$ ) respectively. 
238 Unstandardized coefficients represents how much the biomass production varies with an 239 independent variable COD /TN/TP when all other independent variables are held constant. The 240 statistical significance of each independent variables shown in the "p-value" column is presented 241 in Table 7. The equation to predict the biomass production from $\mathrm{CO}_{2}$ fixation rate is:

242 Predicted biomass production $=0,829-\left(0,065 \times \mathrm{CO}_{2}\right)$

243 Where: $y$ is biomass production $\left(\mathrm{g} \mathrm{L}^{-1} \mathrm{~d}^{-1}\right)$ and $\mathrm{x}$ is $\mathrm{CO}_{2}$ fixation rate $\left(\mathrm{g} \mathrm{L}^{-1} \mathrm{~d}^{-1}\right)$

246 Table 7, Illustrations estimated model coefficients

\section{Table 7. Illustrations estimated model coefficients}

\begin{tabular}{lllll}
\hline Model & Unstandardized & Standardized & t & p-value \\
& Coefficients & Coefficients & & \\
& Beta & \\
\hline
\end{tabular}

\begin{tabular}{llllll}
\hline \multicolumn{7}{c}{ B } & Std. Error & & \\
\hline Constant & $-920,535$ & 334,849 & & $-2,749$ & 0,111 \\
\hline COD & 0,041 & 0,31 & 0,633 & 1,338 & 0,313 \\
\hline TN & 9,102 & 2,603 & 0,682 & 3,496 & 0,073 \\
\hline TP & 3,910 & 4,350 & 0,335 & & 0,899 \\
\hline
\end{tabular}

a. Dependent Variable: Biomass

\begin{tabular}{llllll}
\hline Constant &, 829 &, 458 & & 1,809 &, 113 \\
\hline $\mathrm{CO}_{2}$ &,- 065 &, 694 &,- 035 &,- 093 &, 928
\end{tabular}


252 Biomass production using wastewater sources are currently under intensive invesigation. These 253 studies shows that microalgae have some potential to biomass production, and pollutant removal 254 and can act as source of energy coupled with wastewater treatment. The effect of biomass 255 production and nutrient removal in various wastewater resources are shown in Table 8. Yen et al. 256 (2014) reported about the growth of Chlorella sp.35 in highly concentrated piggery waste water 257 rich in phosphorus and nitrogen [25]. The Chlorella sp.35 algal culture resulted in $60-95.8 \%, 22$ $258-68 \%$ and $34-73.8 \%$ removal of ammonia, total phosphorus and COD of piggery wastewater 259 respectively. Hongyang et al., (2011) observed Chlorella pyrenoidosa cultivated in soybean 260 processing wastewater resulted in an average biomass production of $0.64 \mathrm{~g} \mathrm{~L}^{-1} \mathrm{~d}^{-1}$ and also lead to 261 COD, total nitrogen and total phosphorus removal of $77.8 \pm 5.7 \%, 88.8 \pm 1.0 \%$, and $70.3 \pm 11.4 \%$ 262 respectively in fed-batch process [19]. Wang et al., (2012) investigated the Chlorella pyrenoidosa 263 biomass production in diluted piggery wastewater [23]. The Chlorella pyrenoidosa algal culture 264 resulted in $55.4 \%, 74.6 \%$ and $77.7 \%$ removal of COD, total nitrogen, total phosphorus, 265 respectively from piggery wastewater sample with $1000 \mathrm{mg} / \mathrm{L}$ COD concentration. Ding et al. 266 (2015) discussed about the removal of ammonia, phosphorus and chemical oxygen demand in 267 dairy farm waste water with help of microalgae cultivation [26]. The $20 \%$ dairy farm waste water 268 sample yields $0.86 \mathrm{~g} / \mathrm{L}$ dry weight in 6 days resulted in 83, 92, and 90 removal percentage of 269 ammonia, phosphorus, COD respectively. Gouveia et al. (2016) reported the performance of three 270 different microalgae such as Chlorella vulgaris (Cv), Scenedesmus obliquus (Sc) and Consortium $271 C($ Cons $C)$ for wastewater remediation [27]. The maximum removal was attained by $\mathrm{Cv}, \mathrm{Sc}$ and 
272 ConsC were 84, 95 and 98\% for total nitrogen, 95, 92 and 100\% for phosphorus and 36, 63 and

$27364 \%$ for COD, respectively.

274

275 Table 8. Effect of algal biomass production on removal of COD, TN, and TP from wastewater.

Table 8. Effect of algal biomass production on removal of COD, TN, and TP from wastewater.

Biomass COD \% removal TN \% removal TP \% removal References

production $\left(\mathrm{g} \mathrm{L}^{-1}\right)$

\begin{tabular}{lcccc}
\hline 0,19 & 73,8 & 68 & 95,8 & {$[7]$} \\
\hline 0,64 & 75,8 & 88,8 & 70,3 & {$[8]$} \\
\hline 0,3 & 55,4 & 74,6 & 77,7 & {$[9]$} \\
\hline 0,86 & 90 & 83 & 92 & {$[10]$} \\
\hline 0,1 & 36 & 84 & 95 & {$[11]$} \\
\hline 0,4 & 63 & 95 & 92 & {$[11]$} \\
\hline 0,9 & 64 & 98 & 100 & {$[11]$}
\end{tabular}

277 The percentage removal of COD, TN, and TP in various wastewater resources using different algal

278 species was shown in Table 9. Based on the regression analysis, $R^{2}$ value (also called the 279 coefficient of determination), which is the proportion of variance in the dependent variables such 280 as percentage removal of $\mathrm{COD}, \mathrm{TN}$ and $\mathrm{TP}$ that can be explained by the independent variable 281 biomass. (Technically, accounted by the regression model represented in table 9). Our independent 282 variable biomass explain $41.5 \%, 32.7 \%$ and doesn't have any effect respectively with the 283 variability of our dependent variable such as COD removal, TN removal and TP removal 284 respectively. 
286 Table 9. Regression analysis of biomass production versus percentage removal of COD, TN and 287 TP

\section{Table 9. Regression analysis of biomass production versus percentage removal of COD, TN and TP}

Model summary

\begin{tabular}{lllll}
\hline Model & $\mathrm{R}$ & R Square & Adjusted R Square & Std. Error of the Estimate \\
\hline COD &, $644^{\mathrm{a}}$ &, 415 &, 298 & 14,331 \\
\hline TN &, $571^{\mathrm{a}}$ &, 327 &, 192 & 9,596 \\
\hline TP &, $015^{\mathrm{a}}$ &, 000 &,- 200 & 11,819 \\
\hline
\end{tabular}

a. Predictors: (Constant), Biomass

288

289

290

291

3.5.Phosphorus and nitrogen removal using various phototrophic systems and energy potential of phototrophic technologies

Based upon experimental data by Shoener et al., (2014), the major phototrophic technologies used for algal biomass production include high rate algal ponds (HRAT), photobioreactor (PBR), stirred tank reactor (STR) and algal turf scrubber (ATS). Table 10 presents that the best nitrogen and phosphorus removal were obtained by PBR technology. It also indicates that PBR consumed highest energy when mixing which was done by gas sparging. The rate of gas sparging depends on algal species and their tendency to aggregate. ATS is passive system and it does not require any energy where as HRAP require very less amount of energy for paddlewheels per hectare [21]. 
299 Table 10, Average percent of phosphorus and nitrogen removal, and ranges of energy 300 consumption $\left(\mathrm{kJ} \mathrm{m}^{-3}\right)$ using different phototrophic technologies [21].

Table 10. Average percent of phosphorus and nitrogen removal, and ranges of energy consumption $\left(\mathrm{kJ} \mathrm{m}^{-3}\right)$ using different phototrophic technologies [12]

\begin{tabular}{lccccc}
\hline Technology & $\begin{array}{c}\text { Average percent } \\
\text { removal of } \\
\text { nitrogen }\end{array}$ & $\begin{array}{c}\text { Average percent } \\
\text { removal of }\end{array}$ & Mixing & Pumping & Harvesting \\
& & phosphorus & & & \\
& 67.1 & 52.1 & $3.2-9.6$ & - & $34-170$ \\
\hline HRAP & 78.5 & 93.2 & $6300-$ & $55-58$ & - \\
\hline PBR & & & 13000 & & - \\
& & & & & - \\
\hline Stirred tank & 62.3 & 78.2 & $770-3100$ & $28-31$ & - \\
\hline ATS & 70.5 & 78.6 & - & - & \\
& & & & & \\
\end{tabular}

303 The growth of conditions of algal species depends on light energy and temperature of wastewater 304 system (Table 11). The algal growth can be inhibited as a result of too intense light known as 305 photoinhibition. The photoinhibitation value depends on algal species and growing conditions. The 306 temperature also influence grazing activity, growth rate and species composition of algal 307 communities [12].

308 Table 11. Influence of various physical parameters on growth of algal species in different cultural 309 medium 
Table 11. Influence of various physical parameters on growth of algal species in different cultural medium

Culture medium

Algal species

Light

Photoperiod Temperature

Productivity

$$
\left(\mu \mathrm{mol} \mathrm{m}{ }^{-2} \mathrm{~s}^{-1}\right)
$$

$\left({ }^{\circ} \mathrm{C}\right)$

$\left(\mathrm{g} \mathrm{m}^{-2} \mathrm{~d}^{-1}\right)$

Raw and anaerobically $\quad$ Algal consortia

$40-140$

$16: 8$

22

5

digested dairy manure

Anaerobically digested Algal consortia

$270-390$

23:1

19-24

$5-23$

diary manure

Dairy manure

Chlorella sp.

$110-120$

24

20

$0.58-2.57$

Swine manure

Algal consortia

$240-633$

23:1

23-26

7.1-9.6

Centrate and raw

Mixed culture

$72-104 \quad 16: 8$

$18-27$

$0.5-3.1$

municipal wastewater

\begin{tabular}{llllll}
\hline Municipal watsewater & $\begin{array}{c}\text { S.obliquus and } \\
\text { C. vulgaris }\end{array}$ & 100 & 24 & $23-27$ & 7
\end{tabular}

Municipal and synthetic Mixed culture

230

24

22

2.1-7.7

wastewater

Modified BG11

Mixed culture

$15,30,60,120 \quad 16: 8$

20,30

$0.02-2.9$ 
317 The uncertainity in biomass production (Y) after performing linear fit with uncertainties in $\mathrm{x}$ and

318 y, using a Monte Carlo method is shown in Fig 5. Based on Monte Carlo method, the estimated 319 error on $\mathrm{Y}$ is: 47.78 and Linear fit function: $\mathrm{Y}=(0.053+/-0.019) * \mathrm{X}+(128.64+/-37.74)$, where $320 \mathrm{X}$ is COD concentration. For $\mathrm{X}=\mathrm{TN}$ concentration, based on Monte Carlo method, estimated error 321 on $\mathrm{Y}$ is: 47.95 and Linear fit function: $\mathrm{Y}=(1.25+/-0.442) * \mathrm{X}+(128.71+/-37.89)$. Futhermore, 322 the estimated error on $\mathrm{Y}$ is: 47.75 and Linear fit function: $\mathrm{Y}=(1.19+/-0.419) * \mathrm{X}+(128.25+/-$ 323 37.82), where $\mathrm{X}$ is TP concentration based on Monte Carlo method.
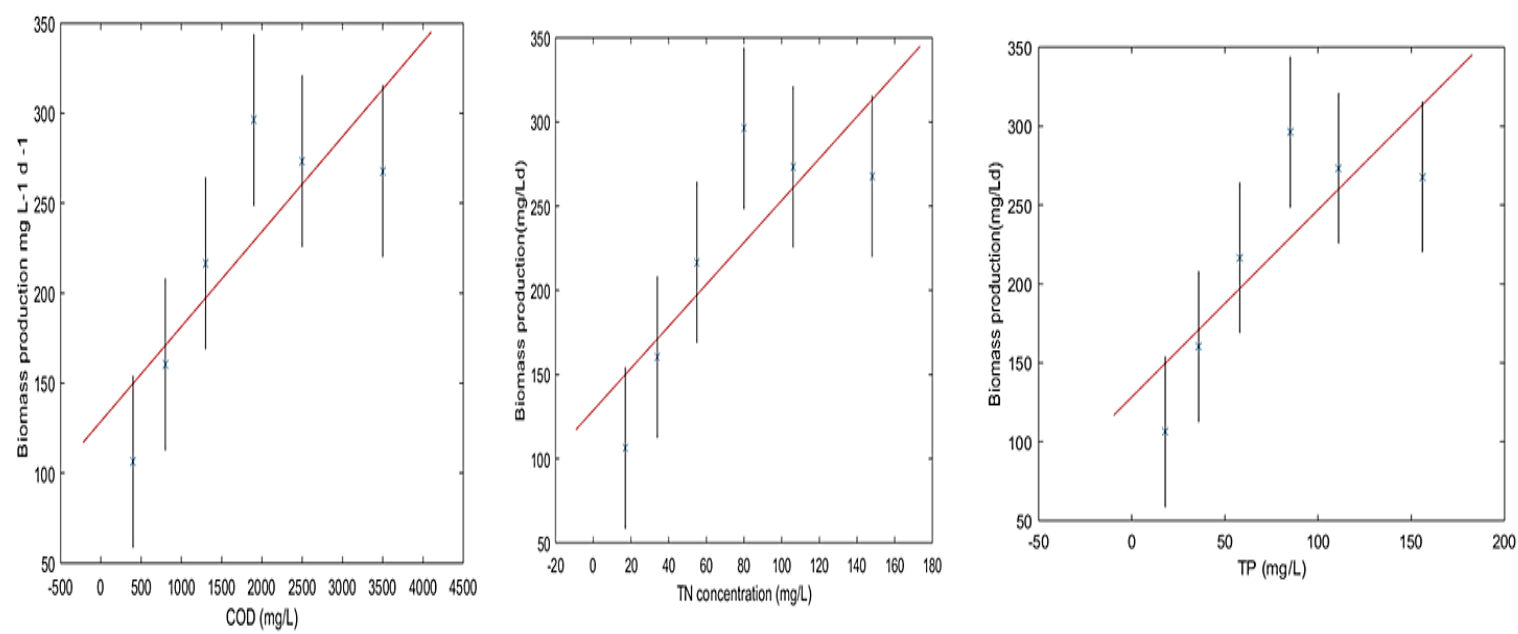

325 Fig5. Uncertainity in biomass productions of Chlorella zofingiensis $\mathrm{mg} \mathrm{L}^{-1} \mathrm{~d}^{-1}$ with respect to 326 $\mathrm{COD}\left(\mathrm{mg} \mathrm{L}^{-1}\right) \mathrm{TN}\left(\mathrm{mg} \mathrm{L}^{-1}\right)$ and $\mathrm{TP}\left(\mathrm{mg} \mathrm{L}^{-1}\right)$ in piggery wastewater effluent

Fig 6 displays linear regression analysis of percentage removal of COD by various algal biomass 329 in different wastewater effluent data represented in Table 8 and illustrates the estimated error of Y (percentage removal of COD) as follows: 14.33, Linear fit function: $\mathrm{Y}=(34.47+/-18.295) * \mathrm{X}+$ 
331 (48.734+/- 10.385), where $\mathrm{X}$ is algal biomass concentration in different kinds of wastewater 332 effluents.
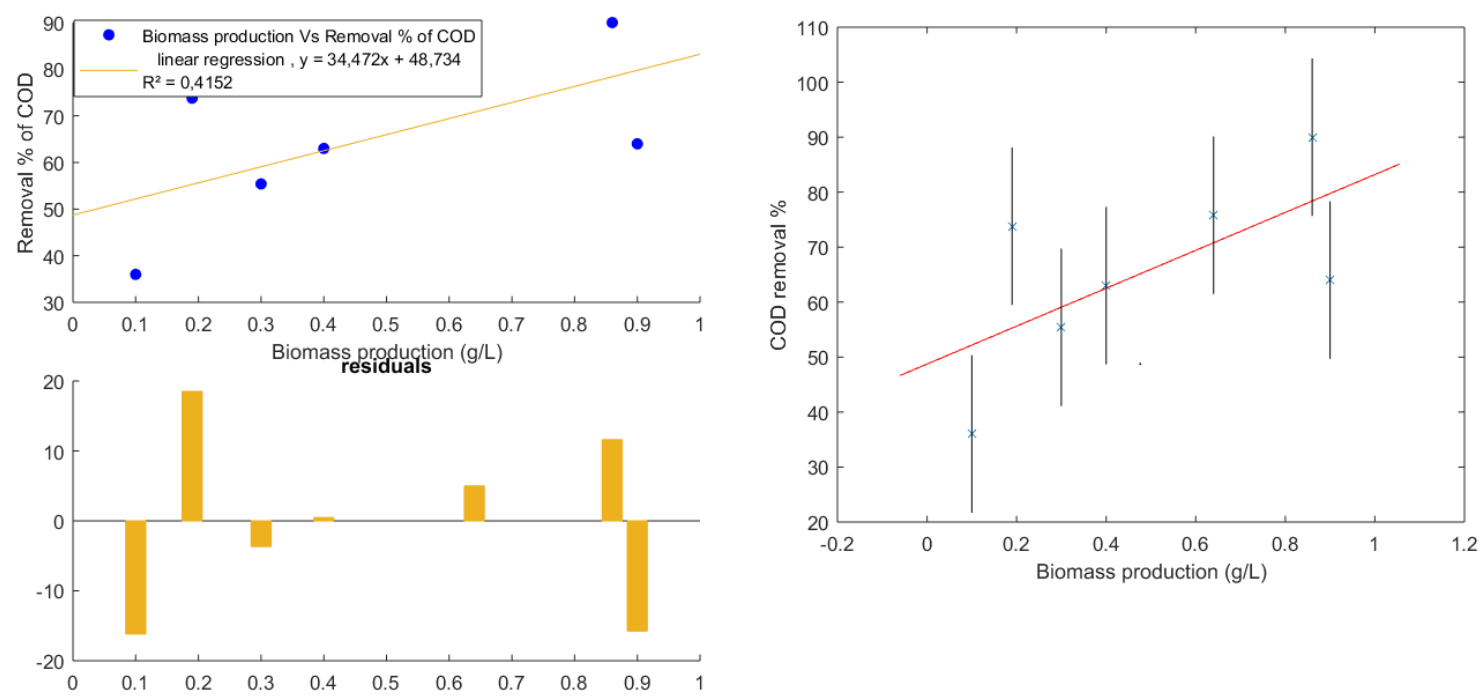

334 Fig 6. Linear regression analysis of percentage removal of COD by various algal biomass and its uncertainity

337 The linear regression analysis of percentage removal of TN by various algal biomass in different 338 wastewater effluent data reported in Table 8 is represented in Fig 7. It also illustrates estimated 339 error on $\mathrm{Y}$ (percentage removal of TN) is: 9.5962, Linear fit function: $\mathrm{Y}=(19.078+/-12.251) *$ 340 $\mathrm{X}+(75.247+/-6.954)$, where $\mathrm{X}$ indicates different algal biomass 

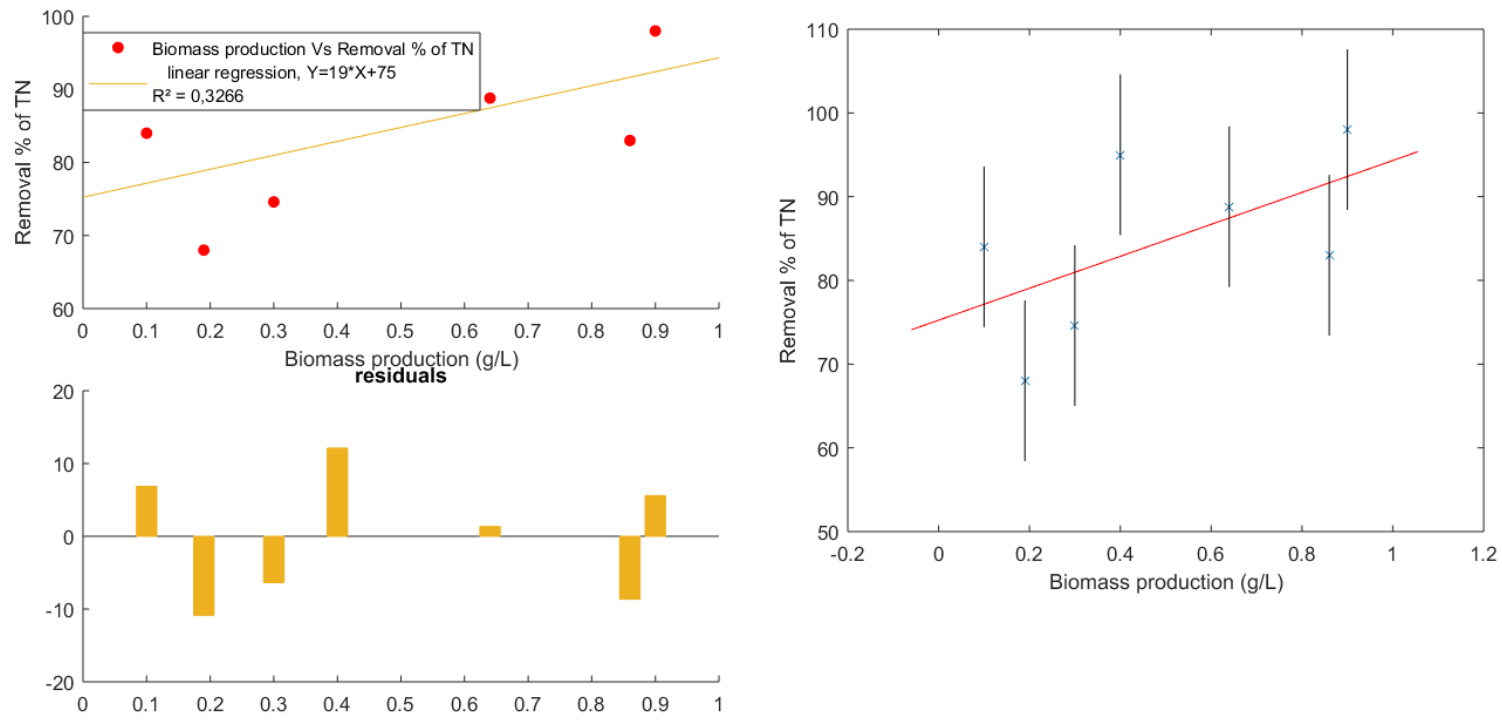

342 Fig 7. Linear regression analysis of percentage removal of $\mathrm{TN}$ by various algal biomass and its 343 uncertainity

345 The Fig 8 shows linear regression analysis of percentage removal of TP by various algal biomass

346 in different wastewater effluent data represented in Table 8. Estimated error on Y (percentage

347 removal in TP concentration) is: 11.8191 and linear fit function: $\mathrm{Y}=(0.507+/-15.089) * \mathrm{X}+$

$348(88.726+/-8.565)$ with respect to $\mathrm{X}$, algal biomass 

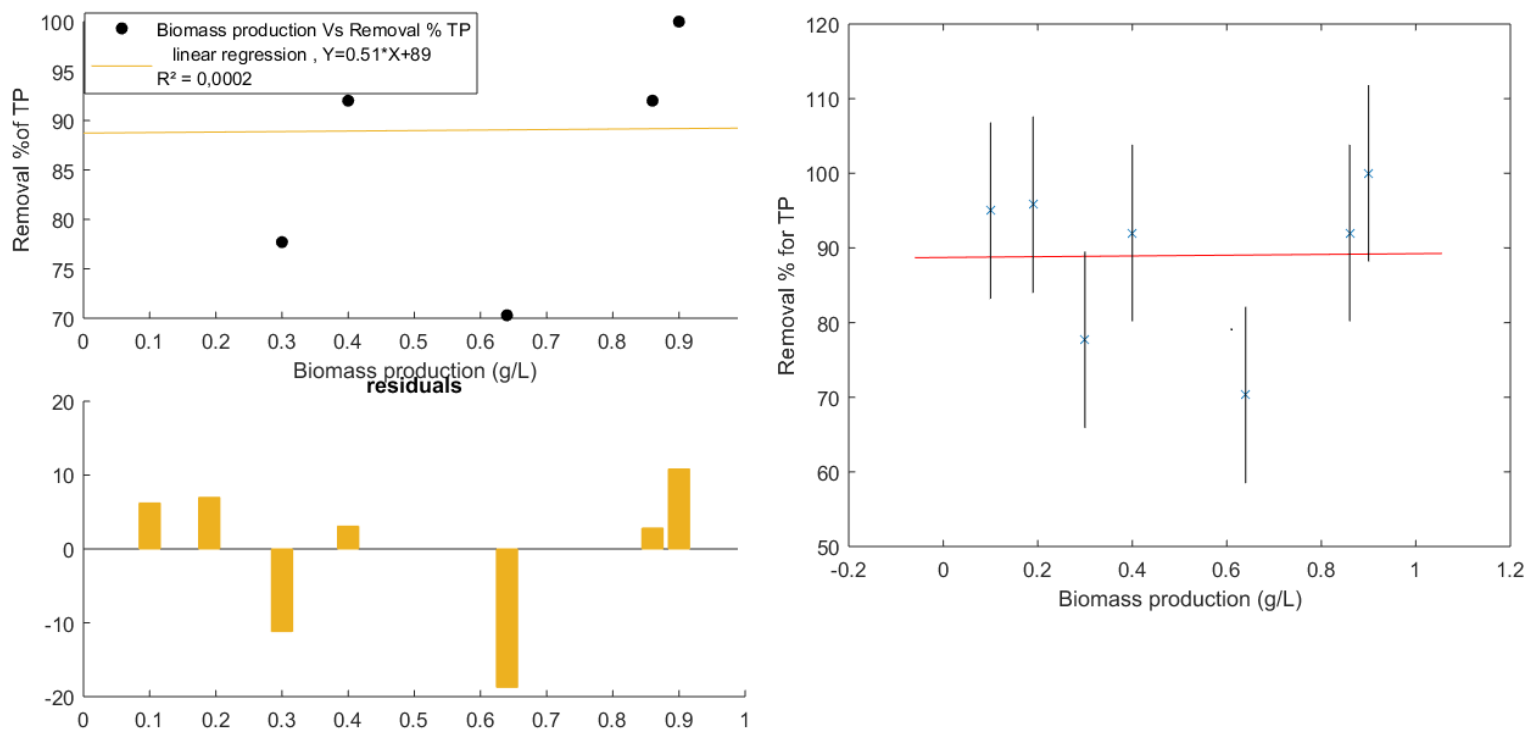

Fig 8. Linear regression analysis of percentage removal of TP by various algal biomass and its uncertainity

\section{Conclusions}

354 Regression equations between algae biomass production and different wastewater variables were 355 developed during algal biomass production from differernt types of wastewater. Lipid productivity 356 contributes $93.7 \%$ of the variability to the dependent variable of biomass production. Other 357 independent variables such as $\mathrm{COD}, \mathrm{TN}, \mathrm{TP}$ and $\mathrm{CO}_{2}$ can explain $66.7 \%, 66.5 \%, 66.7 \%$ and $48 \%$ 358 of the variability of our dependent variable, biomass production. In supplementary to that biomass 359 production has $41.5 \%, 32.7 \%$ effect on the variability of COD removal, TN removal. The general 360 form of the equation to forecast biomass production from COD, TN and TP concentration is:

361 Predicted biomass production $=-920,535+(0,041 \times C O D)+(9,102 \times T N)+$ $362(3,910 \times T P)$. 
363 The uncertainty of regression equation has been quantified using Monte Carlo method. The 364 efficiency of main phototrophic technologies for removal of nitrogen and phosphorus along with 365 energy potential of phototrophic systems were discussed in this research review. The influence of 366 physical parameters on algal biomass was also investigated.

367

\section{References}

369 [1] A. Demirbas, Biodiesel production from vegetable oils by supercritical methanol, J. Sci.

370 Ind. Res. 64 (2005) 858-865.

371 [2] S.P. Singh, D. Singh, Biodiesel production through the use of different sources and

372 characterization of oils and their esters as the substitute of diesel: A review, Renew. Sustain. Energy Rev. 14 (2010) 200-216. doi:10.1016/j.rser.2009.07.017.

374 [3] Y. Li, F. Qiu, D. Yang, X. Li, P. Sun, Preparation, characterization and application of 375 heterogeneous solid base catalyst for biodiesel production from soybean oil, Biomass and Bioenergy. 35 (2011) 2787-2795. doi:10.1016/j.biombioe.2011.03.009.

377 [4] N. Kaur, A. Ali, Lithium ions-supported magnesium oxide as nano-sized solid catalyst for biodiesel preparation from mutton fat, Energy Sources, Part A Recover. Util. Environ. Eff.

[5] M.E. Hums, R.A. Cairncross, S. Spatari, Life-Cycle Assessment of Biodiesel Produced from Grease Trap Waste, Environ. Sci. Technol. 50 (2016) 2718-2726. doi:10.1021/acs.est.5b02667. 
Mandal, G.N. Halder, Production of biodiesel from microalgae through biological carbon capture: a review, 3 Biotech. 7 (2017) 1-21. doi:10.1007/s13205-017-0727-4.

[7] R. Luque, J.C. Lovett, B. Datta, J. Clancy, J.M. Campelo, A.A. Romer, Biodiesel as feasible petrol fuel replacement: a multidisciplinary overview, Energy Environ. Sci. 3 (2010) 1706-1721. doi:10.1039/c0ee00085j.

[8] R. Sayre, Microalgae: The Potential for Carbon Capture, Bioscience. 60 (2010) 722-727. doi:10.1525/bio.2010.60.9.9.

[9] M. Hannon, J. Gimpel, M. Tran, B. Rasala, S. Mayfield, Biofuels from algae: challenges and potential., Biofuels. 1 (2010) 763-784. doi:10.4155/bfs.10.44.

[10] M. Paul Abishek, J. Patel, A. Prem Rajan, Algae Oil: A Sustainable Renewable Fuel of Future., Biotechnol. Res. Int. 2014 (2014) 272814. doi:10.1155/2014/272814.

[11] Anju Dahiaya, Bioenergy - 1st Edition, in: A. Dahiaya (Ed.), Bioenergy Biomass to Biofuels, Elsevier Inc, 2015.

[12] M. Kesaano, R.C. Sims, Algal biofilm based technology for wastewater treatment, Algal Res. 5 (2014) 231-240. doi:10.1016/j.algal.2014.02.003.

[13] W. Zhou, Y. Li, M. Min, B. Hu, H. Zhang, X. Ma, L. Li, Y. Cheng, P. Chen, R. Ruan, Growing wastewater-born microalga Auxenochlorella protothecoides UMN280 on concentrated municipal wastewater for simultaneous nutrient removal and energy feedstock production, Appl. Energy. 98 (2012) 433-440. doi:10.1016/j.apenergy.2012.04.005.

R. Kothari, V. V. Pathak, V. Kumar, D.P. Singh, Experimental study for growth potential 
of unicellular alga Chlorella pyrenoidosa on dairy waste water: An integrated approach for treatment and biofuel production, Bioresour. Technol. 116 (2012) 466-470. doi:10.1016/j.biortech.2012.03.121.

[15] G. Markou, I. Chatzipavlidis, D. Georgakakis, Cultivation of Arthrospira (Spirulina) platensis in olive-oil mill wastewater treated with sodium hypochlorite, Bioresour. Technol. 112 (2012) 234-241. doi:10.1016/j.biortech.2012.02.098.

[16] T.L. G.A. Lutzu, W.Zhang, A5 09593330.2015.pdf, Environ. Technol. 37 (2016) 15681581. doi:10.1080/09593330.2015.1121292.

[17] D. Kargbo, Biodiesel production from municipal sewage sludges, Energy \& Fuels. 24 (2010) 2791-2794. doi:10.1021/ef1001106.

[18] C. Ma, H. Wen, D. Xing, X. Pei, J. Zhu, N. Ren, B. Liu, Molasses wastewater treatment and lipid productivity at low temperature conditions by a microalgal mutant Scenedesmus sp. Z-4, Biotechnol. Biofuels. 10 (2017) 111. doi:10.1186/s13068-017-0797-X.

[19] S. Hongyang, Z. Yalei, Z. Chunmin, Z. Xuefei, L. Jinpeng, Cultivation of Chlorella pyrenoidosa in soybean processing wastewater, Bioresour. Technol. 102 (2011) 98849890. doi:10.1016/j.biortech.2011.08.016.

[20] R. Madadi, A.A. Pourbabaee, M. Tabatabaei, M.A. Zahed, M.R. Naghavi, Treatment of petrochemical wastewater by the green algae chlorella vulgaris, Int. J. Environ. Res. 10 (2016) 555-560.

[21] B.D. Shoener, I.M. Bradley, R.D. Cusick, J.S. Guest, Energy positive domestic wastewater treatment: the roles of anaerobic and phototrophic technologies., Environ. Sci. 
Process. Impacts. (2014) 1204-1222. doi:10.1039/c3em00711a.

427 [22] W. Zhou, Y. Li, M. Min, B. Hu, P. Chen, R. Ruan, Local bioprospecting for high-lipid

428

429

430

431

432

433

434

435

436

437

438

439

440

441

442

443

444

445

446

producing microalgal strains to be grown on concentrated municipal wastewater for biofuel production, Bioresour. Technol. 102 (2011) 6909-6919.

doi:10.1016/j.biortech.2011.04.038.

[23] L. Zhu, Z. Wang, Q. Shu, J. Takala, E. Hiltunen, P. Feng, Z. Yuan, Nutrient removal and biodiesel production by integration of freshwater algae cultivation with piggery wastewater treatment, Water Res. 47 (2013) 4294-4302. doi:10.1016/j.watres.2013.05.004.

[24] G. Yadav, R. Sen, Microalgal green refinery concept for biosequestration of carbondioxide vis-à-vis wastewater remediation and bioenergy production: Recent technological advances in climate research, J. CO2 Util. 17 (2017) 188-206. doi:10.1016/j.jcou.2016.12.006.

[25] D. T. T. Yen, Huan DN, Nga NT. Culturing Chlorella in Anaerobically Digested Piggery Wastewater for Biodiesel Feedstock and Nutrient Removal. J Sci Technol., 99, 2014 , 5-9.

[26] Ding J, Zhao F, Cao Y, Xing L, Liu W, Mei S, et al. Cultivation of microalgae in dairy farm wastewater without sterilization. Int J Phytoremediation 2015, 17, 222-227. doi:10.1080/15226514.2013.876970.

[27] Gouveia L, Graça S, Sousa C, Ambrosano L, Ribeiro B, Botrel EP, et al. Microalgae biomass production using wastewater: Treatment and costs. Scale-up considerations. Algal Res 2016, 16, 167-76. doi:10.1016/j.algal.2016.03.010. 
448 